\title{
Enhancement of rats' single-alternation performance by high food deprivation
}

\author{
ELIZABETH D. CAPALDI \\ Purdue University, Lafayette, Ind. 47907
}

Rats were trained in a straight alley with a single-alternation schedule of reward and nonreward under either high $(11 \mathrm{~g} /$ day $)$ or low $(20 \mathrm{~g} /$ day $)$ food deprivation. Ss under high deprivation were superior in patterning performance to those under low deprivation, the form of this result differing over segments of the alley. In the goal segment, the high-deprivation animals' ran faster on rewarded trials than the low-deprivation animals, while in the start segment, the high-deprivation animals ran more slowly on nonrewarded trials than the low-deprivation animals. It was suggested that increasing food deprivation increases the reward value of food and the aversiveness of nonreward.

The present investigation was concerned with the effect of level of food deprivation on single-alternation patterning of a running response in a straight alley. In a single-alternation schedule, rewarded trials are alternated with nonrewarded trials and patterning is said to occur when speeds on rewarded trials are faster than speeds on nonrewarded trials. It has been reported (Campbell, Crumbaugh, Rhodus, \& Knouse, 1971; Capaldi, 1967 ) that single-alternation patterning is better, i.e., the difference between speeds on nonrewarded and rewarded trials is larger, the larger the reward magnitude employed on rewarded trials. Many have suggested that deprivation level and reward magnitude may influence behavior through a common underlying mechanism and thus have similar effects on performance in many situations (e.g., Bolles, 1967). Thus, it might be expected that single-alternation patterning would be better the higher the deprivation level employed.

\section{SUBJECTS}

The Ss were 20 naive male albino rats purchased from the Holtzman Co., Madison, Wis., about 90 days old upon arrival at the laboratory.

\section{APPARATUS}

The apparatus consisted of a runway painted a flat gray throughout, 57 in. long, $3 \frac{1 / 2}{2}$. wide, with 4 -in.-high sides and covered with $1 / 2$-in. hardware cloth. The startbox was separated from the runway by a metal door which the $\mathrm{E}$ dropped by pushing a button when the $S$ had oriented toward the runway. Dropping the door started the first .01-sec clock. Clock 1 was stopped (start time) and Clock 2 started when the $S$ interrupted a photobeam 12 in. from the door. Clock 2 was stopped (run time) and Clock 3 started when the $S$ broke the second photobeam located 17 in. from the first. Interruption of the third photobeam stopped Clock 3 (goal time). The third photobeam was 12 in. beyond the second photobeam and 3 in. in front of a gray block of wood with a 11/4-in. diam and 3/4-in.-deep hole where pellets were placed. A manually lowered guillotine door, $13 \frac{1}{1} 2$ in. from the rear of the goal compartment, served to confine the $S$ to the goal area.

\section{PROCEDURE}

The study was run by two Es who followed identical procedures, each $\mathrm{E}$ running half the $S s$ in each group. After arrival in the laboratory, the animals were given ad lib water and food for 8 days. On the ninth day, animals were assigned randomly to two groups and the deprivation schedule was begun. Throughout pretraining, the animals were weighed every other day beginning on this day (Day 1). Group High was fed $11 \mathrm{~g}$ of food per day and Group Low $20 \mathrm{~g}$ of food per day throughout the study. On Days 8.10 of pretraining, the animals were handled in groups of five for $10 \mathrm{~min}$ and were fed $12.045 \mathrm{~g}$ Noyes pellets in their home cage 15 min after handling. This amount was subtracted from the daily ration. On Day 11 , animals explored the alley in groups of five for $10 \mathrm{~min}$, photobeams operative, all doors open, no food in the goalbox. On the next day, acquisition began. On Day 1 of acquisition, each animal received two trials, and on the next 26 days, each animal received six trials. All even-numbered trials were rewarded with 12 pellets, all odd-numbered trials were nonrewarded (nonreward confinement duration $=30 \mathrm{sec}$ ). On rewarded trials, animals were removed from the goalbox as soon as they had consumed all the pellets. Each animal was given $60 \mathrm{sec}$ to traverse each alley section. If it failed in this, it was gently guided to the next alley section and $60 \mathrm{sec}$ was recorded for the untraversed section. Throughout experimental training, the animals were weighed every third day. On each day, each animal received all its trials before the next animal received its trials. The intertrial interval "was 30 sec. Thus for every animal évery nonreward (except the first on each day) followed a rewarded trial and every reward followed a nonreward. Animals were run in the sequence Low $S$, High $S$, High $S$, Low $S$, etc. An animal was fed its daily ration minus the amount of food consumed in the goalbox $15 \mathrm{~min}$ after its daily trials.

\section{RESULTS}

Weight differences between groups were highly significant throughout acquisition. The mean weight of the groups over the 27 days of acquisition



Fig. 1. Mean start, run, and goal speed for each group on the rewarded and nonrewarded trials of each day of acquisition. 
were: Group High-303.16g, and Group Low-376.92 g $(75.5 \%$ and $92.8 \%$ of the original ad lib weight of each group, respectively) $\mathrm{F}(1,16)=204.42, \mathrm{p}<.001$.

Times in each alley section were converted to speeds $(1 / \mathrm{sec})$ and between-within analyses were done including deprivation level, $\mathrm{E}$, day, and rewarded vs nonrewarded trials as factors. In all analyses, neither the difference due to $E$ nor any interaction involving $E$ was significant, and this variable is not mentioned further. The mean start, run, and goal speeds for each group on the rewarded and nonrewarded trials of each day of acquisition are shown in Fig. 1. As may be seen in Fig. 1, initially Group $\mathrm{High}$ ran faster than Group Low. Also, speeds on rewarded and nonrewarded trials were initially largely nondifferential for both groups, although there was some tendency in the goal section for speeds to be faster on nonrewarded than on rewarded trials, as had been reported by others in the early trials of partial reinforcement (e.g., Tayler, Wortz, \& Bitterman, 1953). Analyses of speeds on Days 1-9 indicated that the difference due to deprivation level was significant in each alley section [start, $F(1,16)=9.94, \quad p<.01 ; \quad r u n$, $F(1,16)=23.27, \mathrm{p}<.001 ;$ and goal, $F(1,16)=25.28, \mathrm{p}<.001]$, as was the Deprivation Level by Days interaction, with the effect of deprivation level growing smaller over days [start, $\mathrm{F}(8,128)=5.75, \quad \mathrm{p}<.001$; run, $\mathrm{F}(8,128)=6.15, \mathrm{p}<.001 ;$ and goal, $F(8,128)=6.32, \mathrm{p}<.001]$. No other difference was significant in the start and run sections, but in the goal section, speeds were significantly faster on nonrewarded than on rewarded trials $[F(1,16)=6.19$, $\mathrm{p}<.05$ ]

As may also be seen in Fig. 1, when both groups were patterning, the difference between speeds on rewarded and nonrewarded trials was larger for Group High than for Group Low. In the start section, the superior patterning of Group High was due to Group High's running more slowly on nonrewarded trials than Group Low, while in the goal section the superior patterning of Group High was due to Group High's running faster on rewarded trials than Group Low. In the run section, Group High ran faster than Group Low on rewarded trials and showed some tendency to run more slowly than Group Low on nonrewarded trials. Analyses of Days 14.27 indicated that in all sections of the alley, speeds were faster on rewarded than on nonrewarded trials [start, $F(1,16)=79.06, \quad p<.01 ;$ run,
$F(1,16)=82.89, \quad p<.001 ;$ goal, $F(1,16)=61.02, p<.001]$. The effect of deprivation level was significant only in the start section, where it was due to the slow running of Group High on nonrewarded trials [start, $\mathrm{F}(1,16)=11.64 ; \mathrm{p}<.01 ;$ run, $\mathrm{F}<1$; goal, $F(1,16)=1.45, p>.10]$. The Deprivation Level by Rewarded vs Nonrewarded Trials interaction was significant in the start and run sections, reflecting the superior patterning of Group High [start, $\mathrm{F}(1,16)=14.21, \quad \mathrm{p}<.01 ;$ run, $F(1,16)=4.67, p<.05]$, but not in the goal section $[F(1,16)=1.45$, $\mathrm{p}>.10]$. Analyses of speeds on rewarded trials on Days 14-27 indicated that Group High ran significantly faster than Group Low on rewarded trials in the goal section $[F(1,16)=6.05, p<.05]$, but not in the start or run sections [start, $F<1$; run, $F(1,16)=2.13, \quad p>.10]$. Analyses of speeds on nonrewarded trials on Days 14-27 indicated that Group High ran significantly more slowly than Group Low on nonrewarded trials in the start section $[F(1,16)=18.89, p<.001]$, but not in the run or goal (Fs $<1)$.

\section{DISCUSSION}

High deprivation produced a larger difference between speeds on nonrewarded trials and rewarded trials in a single-alternation schedule than did low-deprivation. Ss under high deprivation ran significantly faster than those under low deprivation on rewarded trials in the goal section of the alley and significantly slower than low-deprivation animals on nonrewarded trials in the start section of the alley. When reward magnitude has been varied in a single-alternation schedule, animals receiving large magnitude of reward have been reported to run more slowly on nonrewarded trials than animals receiving a smaller magnitude (Campbell et al, 1971; Experiment 2), or both more slowly on nonrewarded trials and faster on rewarded trials than animals receiving a smaller magnitude (Campbell et al, Experiment 1; Capaldi, 1967). In these studies, alley-section data were not reported, and thus more specific comparison with the present results is not possible. However, as the present results were similar to those obtained when reward magnitude was varied, they support the notions that deprivation level influences the reward value of a given amount of food (Kurtz \& Jarka, 1968) and that increasing deprivation level, like increasing reward magnitude (e.g., Amsel, 1962), increases the aversiveness of nonreward.

The present alley-section data may conform to an interpretation suggested by Amsel (1967). Amsel suggested that in cases where the reward event is unambiguously signaled in the start section of the alley, as in the present experiment, the aversive effect of nonreward or smaller reward is manifest clearly in the start section. But, once the animal begins to run, his behavior is under the control of his expectation of reward. It appears that increasing deprivation level in the present experiment accentuated both of these effects, high-deprivation animals running more slowly on nonrewarded trials in the start section than low-deprivation animals and faster on rewarded trials in the goal section than low-deprivation animals.

Spence, Goodrich, \& Ross (1959) investigated the effects of deprivation level on another variety of go, no-go performance, differential conditioning employing black and white alleys as stimuli. Spence et al reported that deprivation level did not affect go, no-go performance when experience with the two alleys was equated (Experiment 1). However, when twice as many trials were given in the rewarded alley as in the nonrewarded alley (Experiment 2), high deprivation facilitated go, no-go performance, high-deprivation animals running faster in the rewarded alley and more slowly in the nonrewarded alley than low-deprivation animals. Thus, results of Spence et al's Experiment 2 were similar to the present results. However, the basis for this similarity is not immediately obvious. That is, in Spence et al's experiments, experience with the external stimulus of alley color was manipulated, while the order in which each animal experienced the internal stimuli characteristic of reward and nonreward was determined by its own behavior on the first trial (free choice) of each day. In the present investigation, each animal experienced the internal stimuli of reward and nonreward in the same order and an equal number of times, while external alley color remained constant. Thus, although the results of Spence et al's Experiment 2 and the present results are similar, understanding the basis of this similarity must await further research which manipulates internal and external stimuli simultaneously.

\section{REFERENCES}

AMISEL, A. Frustrative nonreward in partial reinforcement and discrimination learning: Some recent history and a theoretical extension. Psychological Review, 1962, 69, 306-328.

AMSEL, A. Partial reinforcement effects on vigor and persistence. In $K$. W. Spence and J. T. Spence (Eds.), Psychology of learning and motivation: Advances in research and theory. Vol. 1. New York: Academic Press, 1967. Pp. 1-65.

BOLLES, R. C. Theory of motivation. New York: Harper \& Row, 1967.

CAMPBELL, P. E.. CRUMBAUGH, C. M. 
RHODUS, D. M.. \& KNOUSE, S. G. Magnitude of partial reward and amount of training in the rat: An hypothesis of sequential effects. Journal of Comparative \& Physiological Psychology, $1971,75,120-128$

CAPALDI, E. J. A sequential hypothesis of instrumental learning. In $K$. W. Spence and J. T. Spence (Eds.), Psychology of learning and motivation: Advances in research and theory. Vol. 1. New York: Academic Press, 1967. Pp. 67-156.

KURTZ, K. H., \& JARKA, R. G. Position preference based on differential food deprivation. Journal of Comparative \& Physiological Psychology, 1968, 66, 518-521.

SPENCE, K. W.. GOODRICH, K. P., \& ROSS, L. W. Performance in differential conditioning and discrimination leaming as a function of hunger and relative response frequency. Journal of Experimental Psychology, 1959, 58 8-16.

TYLER, D. W., WORTZ, E, C., \& BITTERMAN $M$ E. The effect of random and alternating partial reinforcement on resistance to extinction in the rat. American Journal of Psychology, 1953, 66, 57-65.

\section{Hunger and Thirst}

ALVORD, J., CHENEY, C., \& DALEY, M. Development and control of licking in the guinea pig (Cavia porcellus). Behavior Research Methods \& Instrumentation, 1971, $3,14-15$.

BERKLEY, M. A., CRAWFORD, F. T., \& OLIFF, G. A universal food-paste dispenser for use with cats and other animals. Behavior $\mathrm{R}$ e se arc h M e thods \& Instrumentation, 1971, 3, 259-260.

BOITANO, J. J., PATRISSI, G. A., \& SIMONE, S. A. Effects of magnesium pemoline in dimethylsulfoxide on reversal learning, motor activity, and water intake. Psychological Reports, 1971, 28, 71-79.

GALEF, B. G., JR., \& CLARK, M. M. $P$ arent-offspring interactions determine time and place of first ingestion of solid food by wild rat pups. Psychonomic Science, 1971, 25, 15-16.

GALEF, B. G., JR., \& CLARK, M. M. Social factors in the poison avoidance and feeding behavior of wild and domesticated rat pups. Journal of Comparative \& Physiological Psychology, 1971, 75, 341-357.

KEILMAN, P. A. A methodological approach to manipulation of hunger and thirst drive stimuli in the rat. Behavior Research Methods \& Instrumentation, 1971, 3, 287-290.

PAUL, L., MILEY, W. M., \& BAENNINGER, R. Mouse killing by rats: Roles of hunger and thirst in its initiation and maintenance. Journal of Comparative \& Physiological Psychology, 1971, 76, 242-249.

PECK, J. W., \& NOVIN, D. Evidence that osmoreceptors mediating drinking in rabbits are in the lateral preoptic area. Journal of Comparative \& Physiological Psychology, 1971, 74, 134-147.
SANDLER, B. E., VAN GELDER, G. A., KARAS, G. G., \& BUCK, W. B. An operant feeding device for sheep. Journal of the Experimental Analysis of Behavior, 1971, 15, 95-96.

SCHNUR, P. Selective attention: Effect of element preexposure on compound conditioning in rats. Journal of Comparative \& Physiological Psychology, 1971, 76, 123-130.

ZEIGLER, H. P., GREEN, H. L., \& LEHRER, R. Patterns of feeding behavior in the pigeon. Journal of Comparative \& Physiological Psychology, 1971, 76, 468-477.

ZUCKER, I. Light-dark rhythms in rat eating and drinking behavior. Physiology \& Behavior, 1971, 6, 115-126.

Deprivation
CHENG, M.-F., ROZIN, P., \& TEITELBAUM, P. Starvation retards development of food and water regulations. Journal of Comparative \& Physiological Psychology, 1971, 76, 206-218.

CHILLAG, D., \& MENDELSON, J. Schedule-induced airlicking as a function of body-weight deficit in rats. Physiology \& Behavior, 1971, 6, 603-605

COLE, S. O., \& BLASZCZYK. Adaptation to $23 \frac{1}{2}$-hour food deprivation under CRF conditions: A sex comparison. Journal of General Psychology, 1971, 58, 131-135.

DAVIS, J. D., CAMPBELL, C. S., G A L L A G HER, R. J . , \& ZURAKOV, M. A. Disappearance of a humoral satiety factor during food deprivation. Journal of Comparative \& Physiological Psychology, 1971, 75, 476-482.

FIBIGER, H. C., \& CAMPBELL, B. A. Effect of adrenal demedullation on starvation-induced behavioral arousal. Physiology \& Behavior, $1971,6,403-405$.
FILION, R. D. L., FOWLER, S. C., \& NOTTERMAN, J. M. Prefeeding, discontinuance of prefeeding, and force-proportional reinforcement. Journal of General Psychology, $1971,85,145-147$.

HÉTU, R. Deprivation-feeding cycle and locomotor activity of the albino rat in a complex maze. Psychological Record, 1971, 21, 125-130.

JONES, E. C. Drinking behavior of food-deprived rats during feeding sessions. Psychological Reports, 1971, 28, 869-870.

LITNER, J., \& SUBOSKI, M. D. Effects of shock intensity and food deprivation on one-trial discriminated avoidance. Canadian Journal of . Psychology, 1971, 25, 185-194.

MacDONALD, L., \& BARON, A. Recovery from punishment as a function of deprivation level. Psychonomic Science, 1971, 24, 119-121.

MARX, M. H. Performance in extinction as a function of deprivation and incentive in training. Psychonomic Science, $1971,25,45-46$.

MONTI, P. M. Consummatory behavior as a function of deprivation level of the rat. Psychonomic Science, 1971, 25, 23-25.

MYER, J. S., \& KOWELL, A. P. Eating patterns and body weight change of snakes when eating and when food deprived. Physiology \& Behavior, 1971, 6, 71-74.

RENNER, K. E., CRAVENS, R. W., \& WOOLEY, O. W. Relative utility of food rewards as a function of cyclic deprivation or body weight loss in albino rats. Journal of Experimental Psychology, 1971, 90, 102-112.

TARPY, R. M. Effects of food deprivation on spontaneous activity and blood glucose. Psychological Reports, 1971, 28, 463-469.

(Continued on page 15) 